Article

\title{
High Ethanol Contents of Spirit Drinks in Kibera Slums, Kenya: Implications for Public Health
}

\author{
Alex O. Okaru ${ }^{1, *(D)}$, Kennedy O. Abuga ${ }^{1}$ (D), Isaac O. Kibwage ${ }^{1}$ and Dirk W. Lachenmeier ${ }^{2}$ \\ 1 Department of Pharmaceutical Chemistry, University of Nairobi, Nairobi P.O. Box 19676-00202, Kenya; \\ koabuga@uonbi.ac.ke (K.O.A.); okibwage@uonbi.ac.ke (I.O.K.) \\ 2 Chemisches und Veterinäruntersuchungsamt (CVUA) Karlsruhe, Weissenburger Straße 3, \\ 76187 Karlsruhe, Germany; lachenmeier@web.de \\ * Correspondence: alex.okaru@gmail.com; Tel.: +254-726-53-9193
}

Received: 5 September 2017; Accepted: 11 October 2017; Published: 17 October 2017

\begin{abstract}
Cheap licit and artisanal illicit spirit drinks have been associated with numerous outbreaks of alcohol poisoning especially with methanol. This study aimed to evaluate the quality of cheap spirit drinks in Kibera slums in Nairobi County, Kenya. The samples consisted of cheap licit spirits $(n=11)$ and the artisanal spirit drink, 'chang' $a a^{\prime},(n=28)$. The parameters of alcoholic strength and volatile composition were used as indicators of quality and were determined using gas chromatography with flame ionization detection (GC-FID) and gas chromatography-mass spectrometry (GC-MS) respectively. The ranges for alcoholic strength were $42.8-85.8 \%$ vol and $28.3-56.7 \%$ vol for chang'a and licit spirit drinks respectively, while the $\mathrm{pH}$ ranges were 3.3-4.2 and 4.4-4.8 for chang'aa and licit spirit drinks respectively. The majority of volatiles were found in artisanal spirits and they included higher alcohols, ethyl esters and carbonyl compounds. The alcoholic strength of all the artisanal spirits $(100 \%)$ and $91 \%$ of the licit spirits was above the $40 \%$ vol of standard spirits such as vodka. The high ethanol content of the alcohol products was the only element of public health significance in this study.
\end{abstract}

Keywords: artisanal spirit; alcoholic strength; volatiles

\section{Introduction}

The World Health Organization (WHO) categorizes alcoholic beverages into recorded and unrecorded alcohol products [1]. Recorded alcohol products are those whose consumption is registered and licit while unrecorded alcohol includes homemade and artisanal drinks such as chang'aa, unregistered or counterfeited drinks and non-beverage or surrogate alcohols derived from medicinal products, automobile products or cosmetics [1-3]. Chang'aa is an artisanal illicit spirit drink obtained from distillation of liquor from fermented maize grains. The alcoholic content of chang'a is enhanced by addition of sucrose to the fermenting mash before distillation. The production and consumption of the artisanal spirit was first banned in Kenya in 1980 through the Chang'aa Prohibition Act of Kenya but due to the failure to mitigate against the harm arising from the drink, it was legitimized in 2010 by the Alcoholic Drinks Control Bill of 2010 of Kenya. The bill sought to regulate the chang'aa industry with hopes of lowering the prevalence of alcohol poisoning. The Kenya Bureau of Standards (KEBS), a government standards body, also introduced regulation KS 2326:2011 [4] for the spirit.

According to the WHO estimates, the average adult (15+ years) per capita consumption of unrecorded alcohol is $2.5 \mathrm{~L}$ for Kenya (total per capita consumption is $4.3 \mathrm{~L}$ ) corresponding to $58 \%$ [5]. Epidemiological evidence attributes $4 \%$ of the global burden of disease to alcohol and there exists a causal relationship of alcohol with more than 60 diseases such as malignant neoplasms, neuropsychiatric disorders, gastrointestinal diseases and diabetes mellitus, liver cirrhosis, injuries and 
psychosis [6,7] and the high content of ethanol has been cited as the main concern for public health in regard to unrecorded alcohol [3,8-10].

Ethanol and other congeners in spirit drinks can be measured by a variety of methods such as densimetry [11], Fourier transform infrared spectroscopy [12] nuclear magnetic resonance spectroscopy [13], refractometry [14], ultraviolet (UV)-visible (Vis) spectrophotometry [14], enzymatic methods [15], gas chromatography [14,16], high performance liquid chromatography [17], Raman spectroscopy [18-20] and flow injection analysis [15,21,22] among others with the choice of method depending on the type of alcohol product being analysed.

Kibera slum is located $5 \mathrm{~km}$ southwest of Nairobi Central Business District and is characterized by poor sewerage and drainage systems and lack of piped drinking water. The consumption of illicit brews and methanol-laced spirit drinks has been widely reported in Kenya [23] and socially deprived communities such as slum dwellers are more likely to consume such alcohol products. Indeed, the majority of consumers of alcoholic beverages in this low socio-economic setting are more likely to rely on cheap spirit drinks due to economic constraints and the ready availability [24].

Therefore it is important to evaluate the quality of the alcoholic beverages consumed in Kibera slums in context of consumer safety. This study, therefore, aims to determine the content of ethanol and to qualitatively identify the volatile congeners of cheap spirit drinks in the Kibera slums.

\section{Materials and Methods}

\subsection{Samples}

Twenty eight chang'aa samples were obtained from various villages within the Kibera slums. Aliquots measuring 100-200 mL were obtained from each site sampled. The samples were collected in the months of April and May 2015. For security reasons, a guide was used to locate the chang'aa selling households within the sprawling slums. The chang'aa samples were collected into clean plastic bottles and then coded for blind testing. Licit spirit drinks $(n=11)$ were obtained from Soweto and Laini Saba villages of Kibera slums.

\subsection{Chemicals}

High purity water was obtained by distillation using an Aquatron Automatic water still A4000 (Bibby Scientific, Staffordshire, UK) while analytical grade ethanol $(99.9 \% v / v)$ and acetic acid $(99.0 \% v / v)$ used as a working reference standards were from Scharlau (Sentmenat, Spain). Methanol $(99.9 \% v / v)$ and $n$-amyl alcohol $(99.9 \% v / v)$ were from Sigma-Aldrich (Steinheim, Germany) while acetaldehyde $(99.8 \% v / v)$, ethyl acetate $(98.0 \% v / v)$, isobutanol $(99.0 \% v / v)$ and isoamyl alcohol $(99.0 \% v / v)$ were from Merck (Darmstadt, Germany).

\subsection{Alcoholic Strength}

The ethanol content was determined using gas chromatography (GC) with flame-ionization detection (FID). A Shimadzu GC-2010 plus (Shimadzu Corporation, Tokyo, Japan) gas chromatograph operated using GC solution software version 2.42 (Shimadzu Corporation, Tokyo, Japan) with a ZB-WAX plus column $(60 \mathrm{~m} \times 0.25 \mathrm{~mm}$ i.d., film thickness $0.25 \mu \mathrm{m}$ (Phenomenex, Torrance, CA, USA) and flame ionization detector was used. Temperature program used was as follows: $40^{\circ} \mathrm{C}$ hold for $7.5 \mathrm{~min}, 4^{\circ} \mathrm{C} / \mathrm{min}$ to $200{ }^{\circ} \mathrm{C}$, hold for $5 \mathrm{~min}, 15^{\circ} \mathrm{C} / \mathrm{min}$ to $220^{\circ} \mathrm{C}$ hold for $5 \mathrm{~min}$. The temperature of the injection port and detector were set at $260^{\circ} \mathrm{C}$. Nitrogen was used as the carrier gas at a flow rate of $2 \mathrm{~mL} / \mathrm{min}$. The method was validated with respect to linearity, limit of detection (LOD), limit of quantitation (LOQ), precision and recovery in accordance to ICH guidelines [25].

The sample preparation is as described in the EC regulation 2870/2000 for analysis of volatiles and $n$-amyl alcohol was used as internal standard. In brief, $9.0 \mathrm{~mL}$ of the beverage and $1.0 \mathrm{~mL}$ of $n$-amyl alcohol were pipetted into a $100 \mathrm{~mL}$ volumetric flask and made up to volume with deionised water. The resultant mixture was vortexed before injection into the gas chromatographic system. 
One microliter of each sample was injected into the GC-FID system with a split ratio of 100:1. Triplicate injections were made for each sample and a coefficient of variation $(\mathrm{CV})$ of the peak areas determined. A CV $<3 \%$ value was considered adequate for the accurate determination of the alcoholic strength. Quantification was achieved by comparison of peak area ratios of the components to the internal standard against corresponding working reference standards. The range, mean, median and 95th percentile were used to describe the occurrence of the compounds in the alcoholic beverages.

\subsection{Determination of $p H$}

The $\mathrm{pH}$ of the alcohol spirits was determined on 'as-it-is' basis with a Jenway $3510 \mathrm{pH}$ meter (Bibby Scientific, Staffordshire, UK).

\subsection{Volatile Composition and Quantification}

All samples were screened for volatiles including flavor compounds using a Shimadzu QP2010 GC-MS (Shimadzu Corporation, Tokyo, Japan) operated using a GC-MS solution version 2.71 (Shimadzu Corporation, Tokyo, Japan). A split/splitless injector was used anda ZB-WAX plus column (60 $\mathrm{m} \times 0.25 \mathrm{~mm}$ i.d., film thickness $0.25 \mu \mathrm{m}$ (Phenomenex, Torrance, CA, USA). Temperature was programmed thus: $60^{\circ} \mathrm{C}$ hold for $1 \mathrm{~min}, 10^{\circ} \mathrm{C} / \mathrm{min}$ to $190^{\circ} \mathrm{C}$, hold for $5 \mathrm{~min}, 10{ }^{\circ} \mathrm{C} / \mathrm{min}$ to 220 hold for $15 \mathrm{~min}$. The temperature of the injection port and detector were set at $240{ }^{\circ} \mathrm{C}$.

The instrument was operated in the electron impact ionization mode at $70 \mathrm{eV}$ taking scans from 0 to $500 \mathrm{~m} / \mathrm{z}$ in a $1 \mathrm{~s}$ cycle. One microliter of each sample was injected in the splitless mode. The mass spectrum obtained was compared against the NIST I and II mass spectral libraries (Standard Reference Data Program, National Institute of Standards and Technology, MD, USA) for identity. A similarity index $\geq 98 \%$ was considered sufficient for identification of analyte compounds.

Besides ethanol, the volatile compounds namely acetaldehyde, acetic acid, ethyl acetate, 1-propanol, isobutanol and isopentanol were quantified using the GC-FID method and sample preparation procedures described for alcoholic strength (Section 2.3) but the working standards were the respective test compounds. Similarly, triplicate injections were made for each sample and a coefficient of variation (\%RSD) of the peak areas less than $3 \%$ was considered adequate for the accurate determination of the alcoholic strength. Quantification was achieved by comparison of peak area ratios of the components to the internal standard against corresponding working reference standards. The statistical parameters of range, mean, median and 95th percentile were used to describe the occurrence of the compounds in the alcoholic beverages.

\section{Results and Discussion}

\subsection{Sample Distribution}

It was noted that there were few outlets that sold the licit spirit drinks compared to chang'aa. The retail price for about $200 \mathrm{~mL}$ of chang'aa ranged between USD 0.50-1.00 while most of the licit spirit drinks measuring about $250 \mathrm{~mL}$ retailed at USD 1.00. A narrow range of similar and cheap brands of the licit spirit drinks were stocked across the retail outlets visited.

\subsection{Method Validation}

The analytical performance of the GC method used for quantification gave acceptable validation parameters and was considered adequate for the determination of alcoholic strength and volatiles (Table 1). 
Table 1. Method validation.

\begin{tabular}{ccccccccc}
\hline \multirow{2}{*}{ Parameter } & \multicolumn{7}{c}{ Component } \\
\cline { 2 - 9 } & EtOH & Acetaldehyde & Acetic Acid & MeOH & Ethyl Acetate & 1-Propanol & Isobutanol & Isopentanol \\
\hline LOD $^{\mathrm{a}}$ & 0.02 & 0.03 & 0.02 & 0.02 & 0.02 & 0.03 & 0.02 & 0.03 \\
LOQ $^{\mathrm{a}}$ & 0.07 & 0.08 & 0.05 & 0.04 & 0.07 & 0.09 & 0.06 & 0.08 \\
Precision $^{\mathrm{b}}$ & 1.8 & 3.2 & 2.6 & 1.1 & 3.4 & 3.1 & 3.7 & 2.1 \\
Recovery $^{\mathrm{c}}$ & 100.2 & 100.5 & 100.4 & 102 & 98 & 101.3 & 99.5 & 98.7 \\
\hline \multicolumn{8}{c}{ a-mg/100 mL; p.a., b-\% RSD; c-\% mean. }
\end{tabular}

\subsection{Alcoholic Strength}

The alcoholic strength of the chang'aa samples ranged from $42.8 \%$ vol to $85.8 \%$ vol with only eight samples (28.6\%) out of 28 complying with the Kenya standard for chang'aa for alcoholic strength while the rest $(71.4 \%)$ were above the acceptance criteria (35-57\% vol). Similarly, $91 \%$ of the licit spirit drinks had a higher ethanol content than was labelled (range; $28.3 \%$ vol to $56.7 \%$ vol). The alcoholic strength of all the artisanal spirits (100\%) and $91 \%$ of the licit spirits was above the $40 \%$ vol of standard spirits such as vodka. The drinks offered for sale within this slum are thus able to provide high amounts of ethanol in shorter dinking episodes and in smaller volumes thus being able to produce more pronounced intoxication effects. The high alcoholic strength in spirits poses public health risks to the consumers $[2,3,7,10]$. Therefore, there is need for consumer awareness on health hazards attributable to consumption of drinks with high ethanol content. Notably, high alcoholic strength up to $85.8 \%$ $v / v$ in chang'a a samples peculiar since artisanal distillation being uncontrolled may not yield such high contents. Therefore it may be postulated that admixtures of pure ethanol occurred and that such chang'aa may be fraudulently be offered for sale as chang'aa in Kibera slums. However a comprehensive study using more samples would be required to prove this.

\subsection{Analysis of $\mathrm{pH}$}

The $\mathrm{pH}$ range of the chang'a and licit samples ranged between 3.3-4.2 and 4.4-8.8 respectively (Tables 2 and 3). Among the licit drinks, brandies were slightly acidic while whiskey, gin and vodka were slightly basic. The low $\mathrm{pH}$ in brandies is associated with the presence of organic acids and sulfur dioxide or the use of mineral acids to adjust the $\mathrm{pH}$ [26] while slightly basic $\mathrm{pH}$ values may be attributed to treatment with alkalinizing agents to enhance the softness of the taste of the drinks [27]. The chang'aa samples were mildly acidic probably due the presence of organic acids such as acetic acid (Table 2) and succinic acid (Table 4) or acidic additives which were not determined during the study. 
Table 2. Analysis results of chang'aa samples.

\begin{tabular}{|c|c|c|c|c|c|c|c|c|c|c|}
\hline \multirow{2}{*}{ Sample } & \multirow{2}{*}{ Alcoholic Strength $\left(\%\right.$ vol at $\left.20^{\circ} \mathrm{C}\right)$} & \multirow{2}{*}{$\mathrm{pH}$} & \multicolumn{8}{|c|}{ mg/100 mL Pure Alcohol (p.a.) } \\
\hline & & & Acetaldehyde & Acetic Acid & Methanol & Ethyl Acetate & 1-Propanol & Isobutanol & Isopentanol & Higher Alcohols \\
\hline K01 & $66.1 \pm 0.22$ & 3.3 & 58.6 & 29.6 & 1.7 & 0.8 & 12.9 & 7.4 & 93.2 & 114 \\
\hline K02 & $85.8 \pm 0.32$ & 3.8 & 44.5 & 32.2 & 1.8 & 0.3 & 4.3 & 2.4 & 25.5 & 32 \\
\hline K03 & $76.0 \pm 0.17$ & 3.9 & 32.6 & 13.3 & 2.5 & 0.3 & 12.8 & 4.6 & 124.8 & 142 \\
\hline K04 & $58.7 \pm 0.25$ & 3.7 & 100.6 & 43.6 & 5.1 & 2.5 & 23.2 & 11.4 & 160.6 & 195 \\
\hline K05 & $63.6 \pm 0.36$ & 3.7 & 101.0 & 46.2 & 3.2 & 3.1 & 27.8 & 14.1 & 191.9 & 234 \\
\hline K06 & $60.5 \pm 0.59$ & 3.8 & 46.6 & 20.5 & 4.4 & 3.9 & 22.6 & 13.3 & 229.2 & 265 \\
\hline K07 & $72.7 \pm 0.33$ & 3.9 & 36.0 & 3.6 & 4.2 & 1.5 & 37.7 & 5.7 & 279.8 & 323 \\
\hline K08 & $48.8 \pm 0.38$ & 3.8 & 34.8 & 12.2 & 4.2 & 2.3 & 13.3 & 14.5 & 306.5 & 334 \\
\hline K09 & $68.8 \pm 0.10$ & 4.2 & 24.8 & 21.0 & 1.9 & 1.1 & 2.0 & 13.4 & 71.9 & 87 \\
\hline K10 & $49.7 \pm 027$ & 3.7 & 1.1 & 2.7 & ND & 0.3 & 2.2 & 1.0 & 17.8 & 21 \\
\hline K11 & $62.5 \pm 0.20$ & 3.8 & 0.3 & 0.1 & ND & 0.2 & 2.6 & 1.1 & 25.8 & 29 \\
\hline K12 & $45.5 \pm 0.23$ & 3.7 & 0.8 & 1.0 & 0.1 & 0.2 & 2.0 & 1.0 & 15.5 & 18 \\
\hline K13 & $59.7 \pm 0.11$ & 3.9 & 0.5 & 1.2 & 0.3 & 0.2 & 1.9 & 2.7 & 63.9 & 69 \\
\hline K14 & $70.7 \pm 0.62$ & 3.8 & 1.5 & 1.1 & ND & ND & 1.6 & 0.9 & 8.2 & 11 \\
\hline K15 & $58.0 \pm 0.69$ & 3.6 & 3.2 & 2.7 & 0.2 & 0.2 & 1.3 & 0.9 & 15.8 & 18 \\
\hline K16 & $53.3 \pm 0.48$ & 3.6 & 3.6 & 2.4 & 0.4 & 0.2 & 1.7 & 0.7 & 13.2 & 16 \\
\hline K17 & $76.9 \pm 0.92$ & 4.1 & 2.1 & 0.3 & 0.4 & 0.2 & 2.0 & 0.9 & 14.1 & 17 \\
\hline K18 & $59.1 \pm 0.63$ & 3.9 & 1.7 & 0.9 & 0.1 & 0.2 & 1.2 & 1.2 & 26.9 & 29 \\
\hline K19 & $42.8 \pm 0.56$ & 3.6 & 2.0 & 0.7 & 0.1 & ND & 1.0 & 0.7 & 15.8 & 18 \\
\hline K20 & $59.0 \pm 0.34$ & 3.9 & 1.7 & 2.2 & 0.5 & 0.2 & 2.3 & 0.9 & 14.9 & 18 \\
\hline K21 & $68.1 \pm 0.11$ & 4.2 & 0.6 & 0.3 & 0.8 & ND & 5.1 & 0.9 & 16.9 & 23 \\
\hline K22 & $76.2 \pm 0.63$ & 4.2 & 0.6 & 0.1 & 0.9 & ND & 6.5 & 1.1 & 23.9 & 31 \\
\hline K23 & $63.6 \pm 0.51$ & 3.9 & 0.9 & 0.7 & 0.5 & 0.1 & 2.2 & 2.2 & 59.9 & 64 \\
\hline K24 & $49.7 \pm 0.55$ & 3.9 & 0.8 & 0.2 & 0.5 & ND & 3.6 & 0.5 & 10.5 & 15 \\
\hline K25 & $54.6 \pm 0.85$ & 4.1 & 0.5 & 0.4 & 0.3 & ND & 2.0 & 0.5 & 7.6 & 10 \\
\hline K26 & $74.4 \pm 0.11$ & 3.9 & 0.7 & 0.4 & 0.5 & 0.9 & 2.0 & 0.8 & 15.3 & 18 \\
\hline K27 & $66.6 \pm 0.40$ & 3.8 & 0.4 & 0.6 & 0.5 & 0.2 & 2.1 & 0.9 & 26.1 & 29 \\
\hline K28 & $51.6 \pm 0.39$ & 3.3 & 2.4 & 2.8 & 0.1 & 0.3 & 1.2 & 0.5 & 9.2 & 11 \\
\hline Range & $42.8-85.8$ & $3.3-4.2$ & $0.3-101$ & $0.1-46$ & ND-5.1 & ND-3.9 & $1.0-37.7$ & $0.5-14.5$ & $7.6-307$ & $10-334$ \\
\hline Median & 61.5 & 3.8 & 1.9 & 1.7 & 0.5 & 0.3 & 2.2 & 1.0 & 24.7 & 29.3 \\
\hline Mean & $62.3 \pm 10.64$ & 3.8 & 18.0 & 8.7 & 1.4 & 0.9 & 7.2 & 3.8 & 67.3 & 78.3 \\
\hline P95 & 81.8 & 4.2 & 85.9 & 39.6 & 4. 3 & 3.1 & 26.2 & 13.8 & 262.1 & 302.9 \\
\hline Kenyan limit & $35-57$ & - & 126.4 & - & 5 & $580 *$ & - & - & - & - \\
\hline
\end{tabular}

established for the parameter, ${ }^{*}$ total esters expressed as ethyl acetate. 
Table 3. Selected analytical results of licit spirits.

\begin{tabular}{|c|c|c|c|c|c|}
\hline \multirow{2}{*}{ Sample } & \multirow{2}{*}{ Type } & \multirow{2}{*}{ Alcoholic Strength $\left(\%\right.$ vol at $\left.20^{\circ} \mathrm{C}\right)$} & \multirow{2}{*}{$\mathrm{pH}$} & \multicolumn{2}{|c|}{ mg/100 mL Pure Alcohol } \\
\hline & & & & Methanol & Isopentanol \\
\hline $\mathrm{C} 02$ & Gin & $41.7 \pm 0.32$ & 7.6 & 1.0 & ND \\
\hline $\mathrm{C} 03$ & Vodka & $28.3 \pm 0.19$ & 7.8 & 0.4 & ND \\
\hline $\mathrm{C} 07$ & Brandy & $45.8 \pm 0.33$ & 4.8 & ND & ND \\
\hline $\mathrm{C} 08$ & Brandy & $49.1 \pm 0.38$ & 4.8 & 0.1 & ND \\
\hline $\mathrm{C} 13$ & Vodka & $56.7 \pm 0.15$ & 7.7 & ND & ND \\
\hline $\mathrm{C} 14$ & Vodka & $49.7 \pm 0.49$ & 8.5 & ND & ND \\
\hline $\mathrm{C} 16$ & Brandy & $56.1 \pm 0.42$ & 4.4 & 0.1 & 1.7 \\
\hline $\mathrm{C} 17$ & Vodka & $50.4 \pm 0.90$ & 8.1 & 0.04 & ND \\
\hline $\mathrm{C} 23$ & Vodka & $57.2 \pm 0.52$ & 8.8 & 0.6 & ND \\
\hline $\mathrm{C} 24$ & Gin & $51.3 \pm 0.47$ & 8.4 & 0.4 & ND \\
\hline $\mathrm{C} 25$ & Vodka & $48.7 \pm 0.34$ & 7.7 & ND & ND \\
\hline
\end{tabular}

Table 4. Volatile constituents identified in chang'aa samples.

\begin{tabular}{|c|c|c|c|c|c|c|c|c|c|c|c|}
\hline \multirow{2}{*}{ Sample } & \multicolumn{11}{|c|}{ Sample Composition } \\
\hline & ACA & $\mathrm{ACO}$ & ACT & 2,3-Bu & ACON & ECPL & ECPN & FA & Suc & EL & EPT \\
\hline RT (min) & 5.3 & 5.8 & 6.2 & 7.0 & 11.7 & 13.7 & 16.9 & 17.2 & 17.4 & 20.3 & 28.8 \\
\hline K01 & - & - & - & - & - & - & - & - & - & - & - \\
\hline K02 & + & - & - & - & - & - & - & - & - & - & - \\
\hline K03 & - & - & - & - & - & - & - & - & - & - & - \\
\hline K04 & - & - & - & - & - & + & + & - & + & - & - \\
\hline K05 & - & - & - & - & - & - & + & - & - & - & - \\
\hline K06 & - & - & - & - & - & - & + & - & - & - & - \\
\hline K07 & + & - & - & - & + & - & + & + & - & + & + \\
\hline K08 & + & - & - & - & - & - & - & - & + & - & - \\
\hline K09 & - & - & - & - & - & - & - & + & - & - & - \\
\hline K10 & - & - & - & - & - & - & + & + & - & - & - \\
\hline K11 & + & - & - & - & - & - & + & - & - & + & - \\
\hline K12 & + & - & - & - & + & - & - & - & - & - & - \\
\hline K13 & + & - & - & - & - & - & - & - & - & - & - \\
\hline K14 & - & - & - & - & - & - & + & + & + & + & - \\
\hline K15 & - & - & - & - & - & - & + & - & + & - & - \\
\hline K16 & - & - & - & - & - & - & + & - & + & - & - \\
\hline K17 & + & - & - & - & - & - & + & - & - & + & - \\
\hline K18 & + & - & - & - & - & - & + & - & + & + & - \\
\hline K19 & + & - & - & - & - & - & - & + & - & - & - \\
\hline K20 & - & - & - & - & - & - & + & + & - & + & - \\
\hline K21 & + & + & + & + & - & - & + & + & - & + & + \\
\hline K22 & + & + & + & + & + & + & + & - & - & + & + \\
\hline K23 & + & + & + & + & + & - & + & + & - & - & - \\
\hline K24 & + & + & + & + & + & - & + & + & - & - & - \\
\hline K25 & + & + & + & + & + & - & + & + & - & + & - \\
\hline K26 & + & - & - & + & - & - & + & - & - & - & - \\
\hline K27 & + & - & - & + & - & - & + & - & - & - & - \\
\hline K28 & + & - & - & + & - & + & - & + & - & - & - \\
\hline
\end{tabular}

ACA-Acetaldehyde, ACO-Acetone, ACT-Acetal, 2,3-but-2,3-butadione, ACON-Acetoin, FA-2-Furfural, ECPL-Ethyl caprylate, ECPO-Ethyl caproate, ECPN—Ethyl caprinate, EL-Ethyl laurate, EPT—Ethyl palmitate, EPD—Ethyl pentadecanoate, Hep-Heptanoic acid, Succ-Succinic acid and PhEt-Phenethyl alcohol, +-Detected, -Not detected, Hep. was only detected in K28 while EPD was in K03 and K04, ECPO in K21.

\subsection{Volatiles Quantified}

Acetaldehyde may have arisen from inadequate hygiene and bacterial spoilage of the mashes and production equipment, use of yeast strains with a high production of acetaldehyde and oxidation of 
ethanol by $\mathrm{O}_{2}$ during the fermentation under aerobic conditions. Further oxidation of acetaldehyde may result in formation of acetic acid [28]. Acetaldehyde was detected in the chang'aa samples only in the range of $0.3-101 \mathrm{mg} / 100 \mathrm{~mL}$ of pure alcohol (p.a.) with a mean content of $17.5 \mathrm{mg} / 100 \mathrm{~mL}$ p.a. However, these levels were within the limits $(126.4 \mathrm{mg} / 100 \mathrm{~mL}$ p.a.) set in the Kenyan standard for chang'aa (Table 2).

Determination of the methanol content is important because of the toxicity of its metabolites, formaldehyde and formic acid. Despite the numerous cases of methanol poisoning reported in Kenya, the current study did not detect methanol levels above the Kenyan limit of $5 \mathrm{mg} / 100 \mathrm{~mL}$ p.a. and European Union limit for vodka of $10 \mathrm{mg} / 100 \mathrm{~mL}$ p.a., respectively (mean content was found to be $1.4 \mathrm{mg} / 100 \mathrm{~mL}$ p.a.). The low levels of methanol are expected since the production process of the artisanal spirit involves natural fermentation of maize grains and use of high amounts of sugar. Methanol poisoning may only be caused by ad-mixture with the commercial solvent.

Ethyl acetate results from acetyl-CoA during fermentation because of the continuous oxidation of ethanol to acetic acid and the subsequent esterification [28]. Increased ethyl acetate and 1-propanol concentrations are indicative of prolonged storage of the raw material and probable acetic bacterial spoilage. The highest concentration of ethyl acetate in the chang'aa samples was $3.9 \mathrm{mg} / 100 \mathrm{~mL}$ p.a. with a mean of $0.7 \mathrm{mg} / 100 \mathrm{~mL}$ p.a. No ethyl acetate was detected in the licit brew samples. Nevertheless, all the chang'aa samples complied with the Kenyan limit for ethyl acetate. The mean content of 1-propanol in chang'aa was $7.2 \mathrm{mg} / 100 \mathrm{~mL}$ p.a. (range 1.0-37.7 mg/100 mL p.a.). The Kenyan limit for higher alcohols in chang'aa is qualitative since it prescribes that no precipitate shall be formed. However, artisanally and naturally produced spirits from grains and sugars and even commercially rectified spirits always contain some amount of higher alcohols. Therefore, all the chang'aa samples analyzed did not comply with Kenyan limit but are still judged as of no concern to public health [29].

Isobutanol (2-Methyl-1-propanol) concentration in the chang'aa was in the range of $0.5-15 \mathrm{mg} / 100 \mathrm{~mL}$ p.a. with a mean of $3.8 \mathrm{mg} / 100 \mathrm{~mL}$ p.a. while the isoamyl alcohol was in the range of $7.6-307 \mathrm{mg} / 100 \mathrm{~mL}$ p.a. with a mean of $67.3 \mathrm{mg} / 100 \mathrm{~mL}$ p.a. (Table 2). One sample of the licit drinks contained isopentanol (1.7 mg/100 mL p.a.) (Table 3). Isopentanol is formed during fermentation by deamination and decarboxylation reactions from isoleucine [30]. Elevated concentrations of isoamyl alcohol contribute negatively to the aroma of spirit drinks [31]. The mean content of higher alcohols was $78.3 \mathrm{mg} / 100 \mathrm{~mL}$ p.a., which is the sum total of 1-propanol, isobutanol and isopentanol, in chang'aa samples. However, this has limited public health significance since these levels are by far lower than the preliminary guideline of $1000 \mathrm{~g} / \mathrm{hL}$ p.a. for the sum of all higher alcohols thatis associated with acute and chronic effects such as liver cirrhosis [32]. The level $(1000 \mathrm{~g} / \mathrm{hL})$ is higher than the concentrations usually found in both legal alcoholic beverages and surrogate alcohols [33].

\subsection{Volatiles Detected}

The volatile congeners qualitatively detected included esters and carbonyl compounds and these are known to confer distinct characteristics to the products. The volatile congeners originate from flavoring agents, raw materials and the subsequent processes such as mashing, fermentation, distillation and aging. The relative concentrations of these compounds vary with some contributing to the flavor and odor of the alcohol products. Nonetheless, the concentrations of these agents may have little relationship to the perceived olfactory characteristics of a product [34]. The majority of the volatiles were observed in artisanal spirits compared to licit spirits and there were differences in 'typicities' of the volatile profiles of artisanal spirits since the starting materials and art of brewing differ among producers from different communities in the slums. Ethyl acetate, 1-propanol, isobutanol, isopentanol, ethyl lactate, 2,3-butanediol and acetic acid were present in all samples of the artisanal spirits.

Carbonyl compounds result from spontaneous or microbially-mediated oxidation. The carbonyls detected in the samples include acetaldehyde, acetone, acetoin, furfuryl alcohol, 5-hydroxymethyl furfural and furfural (Table 4). Furfural (2-furfural) and 5-hydroxymethyl furfural (HMF) are furanic 
derivatives formed during distillation due to dehydration of residual fermentable pentose sugars, xylose and rhamnose, respectively. The dehydration is caused by unfavorable fermentation conditions such as heating in acid conditions and/or Maillard reaction [35]. In our study, furfural was detected in ten chang'aa samples while 5-HMF occurred in only one of the licit spirit drinks, C13. This could be attributed to the uncontrolled distillation conditions employed in the production of chang'aa. Phenylethanol, a tail fraction, was detected in 26 of the 28 chang'aa samples while it was not detected in the licit spirit drinks (Table 4). This could be attributed to the inefficient distillation conditions employed in the production of chang'aa. Other components detected in licit spirit, C24, were benzyl alcohol and $\alpha$-terpineol, a terpenoid used as a flavoring agent.

Esters are responsible for the sensory characteristics of spirits, giving them a pleasant fruity smell and they arise during fermentation processes of organic acids and alcohols. Ethyl esters of fatty acids are the most important aroma compounds in the spirit drinks. They are enzymatically produced during yeast fermentation and from ethanolysis of acyl-CoA that is formed during fatty acids synthesis or degradation [36]. Six ethyl esters were identified in illicit spirits and one in licit spirit drink, C16, namely ethyl caprylate, ethyl acetate, ethyl butyrate and ethyl caproate. Ethyl lactate serves to stabilize the distillate flavor and softens the harsh flavor characteristics present in low concentrations. The presence of lactic acid bacteria increases its concentration and contributes negatively to the distillate organoleptic quality [36]. Ethyl lactate was detected in all chang'aa samples and but not in licit spirit drinks.

\subsection{Public Health Implications}

The consumption and production of traditional drinks such as chang'aa is reported to be high in sub-Saharan Africa [37]. These products are not labelled about their alcoholic strength and thus consumers may use organoleptic characteristics to make a judgement on ethanol content, which is difficult if impossible, however [10]. Research has shown that that consumers tend to ingest more volume of alcohol [10] and therefore are at a greater risk for health due to high ethanol amounts.

Although high alcoholic strengths have been reported in other studies conducted in Poland [10], it is worth noting that artisanal distillation of grains to produce chang'aa would certainly not achieve such high alcoholic strengths that have been reported in this study. Plausibly, these extreme ethanol strengths may be from admixtures of rectified industrial ethanol into the traditional spirit, chang'aa. Further comprehensive study is required to investigate this finding using more samples.

\section{Conclusions}

This study in Kenya, which found extreme and unlabeled alcoholic strengths in unrecorded spirits, corroborates results from other countries (see [38,39]) namely that the only common element is the higher alcoholic strength of unrecorded products compared with licit spirits. The public health relevance of this observation is especially grave because the higher content of ethanol is not labelled on the products and thus the consumer may ingest more alcohol than with recorded spirits.

Acknowledgments: The authors are grateful to the German Academic Exchange Service (DAAD) for the scholarship awarded to Alex Okaru and the Deans Committee, University of Nairobi, for funding this research.

Author Contributions: A.O.O., K.O.A., I.O.K., D.W.L. conceived the study and helped to draft the manuscript, organized data and revised the final version of the manuscript. All authors contributed to the interpretation of findings, read and approved the final manuscript.

Conflicts of Interest: The authors declare no conflict of interest.

\section{References}

1. World Health Organization. Global Information System on Alcohol and Health (GISAH); World Health Organization: Geneva, Switzerland, 2016. 
2. Lachenmeier, D.W.; Sarsh, B.; Rehm, J. The composition of alcohol products from markets in Lithuania and Hungary, and potential health consequences: A pilot study. Alcohol Alcohol. 2009, 44, 93-102. [CrossRef] [PubMed]

3. Rehm, J.; Kanteres, F.; Lachenmeier, D.W. Unrecorded consumption, quality of alcohol and health consequences. Drug Alcohol Rev. 2010, 29, 426-436. [CrossRef] [PubMed]

4. Kenya Bureau of Standards. Traditional Spirit (Chang'aa)_Specification; KS 2326:2011; Kenya Bureau of Standards: Nairobi, Kenya, 2011.

5. World Health Organisation. Global Status Report on Alcohol and Health; World Health Organisation: Geneva, Switzerland, 2014.

6. Guilbert, J.J. The world health report 2002-Reducing risks, promoting healthy life. Educ. Health (Abingdon) 2003, 16, 230.

7. Rehm, J.; Mathers, C.; Popova, S.; Thavorncharoensap, M.; Teerawattananon, Y.; Patra, J. Alcohol and Global Health 1 Global burden of disease and injury and economic cost attributable to alcohol use and alcohol-use disorders. Lancet 2009, 373, 2223-2233. [CrossRef]

8. Carey, K.; Kinney, J.; Eckman, M.; Nassar, A.; Mehta, K. Chang'aa Culture and Process: Detecting Contamination in a Killer Brew. Procedia Eng. 2015, 107, 395-402. [CrossRef]

9. Lachenmeier, D.W.; Rehm, J. What is the main source of human exposure to higher alcohols and is there a link to immunotoxicity? Immunopharmacol. Immunotoxicol. 2013, 35, 451-453. [CrossRef] [PubMed]

10. Lachenmeier, D.W.; Ganss, S.; Rychlak, B.; Rehm, J.; Sulkowska, U.; Skiba, M.; Zatonski, W. Association between quality of cheap and unrecorded alcohol products and public health consequences in Poland. Alcohol. Clin. Exp. Res. 2009, 33, 1757-1769. [CrossRef] [PubMed]

11. Lachenmeier, D.W.; Burri, P.A.; Fauser, T.; Frank, W.; Walch, S.G. Rapid determination of alcoholic strength of egg liqueur using steam distillation and oscillation-type densimetry with peristaltic pumping. Anal. Chim. Acta 2005, 537, 377-384. [CrossRef]

12. Lachenmeier, D.W. Rapid quality control of spirit drinks and beer using multivariate data analysis of Fourier transform infrared spectra. Food Chem. 2007, 101, 825-832. [CrossRef]

13. Monakhova, Y.B.; Kuballa, T.; Lachenmeier, D.W. Nontargeted NMR analysis to rapidly detect hazardous substances in alcoholic beverages. Appl. Magn. Reson. 2012, 42, 343-352. [CrossRef]

14. Association of Official Analytical Chemists (AOAC). Official Methods of Analysis of AOAC International, Official Method 920.56, 17th ed.; AOAC International: Gaithersburg, MD, USA, 2002.

15. Rangel, A.O.; Tóth, I.V. Enzymatic determination of ethanol and glycerol by flow injection parallel multi-site detection. Anal. Chim. Acta 2000, 416, 205-210. [CrossRef]

16. Wang, M.; Choong, Y.; Su, N.; Lee, M. A rapid method for determination of ethanol in alcoholic beverages using capillary gas chromatography. J. Food Drug Anal. 2003, 11, 133-140.

17. Yarita, T.; Nakajima, R.; Otsuka, S.; Ihara, T.; Takatsu, A.; Shibukawa, M. Determination of ethanol in alcoholic beverages by high-performance liquid chromatography-flame ionization detection using pure water as mobile phase. J. Chromatogr. A 2002, 976, 387-391. [CrossRef]

18. Mendes, L.S.; Oliveira, F.C.C.; Suarez, P.A.Z.; Rubim, J.C. Determination of ethanol in fuel ethanol and beverages by Fourier transform (FT)-near infrared and FT-Raman spectrometries. Anal. Chim. Acta 2003, 493, 219-231. [CrossRef]

19. Boyaci, I.H.; Genis, H.E.; Guven, B.; Tamer, U.; Alper, N. A novel method for quantification of ethanol and methanol in distilled alcoholic beverages using Raman spectroscopy. J. Raman Spectrosc. 2012, 43, 1171-1176. [CrossRef]

20. Frausto-Reyes, C.; Medina-Gutiérrez, C.; Sato-Berrú, R.; Sahagún, L.R. Qualitative study of ethanol content in tequilas by Raman spectroscopy and principal component analysis. Spectrochim. Acta Part A Mol. Biomol. Spectrosc. 2005, 61, 2657-2662. [CrossRef] [PubMed]

21. Salgado, A.M.; Folly, R.O.M.; Valdman, B.; Cos, O.; Valero, F. Colorimetric method for the determination of ethanol by flow injection analysis. Biotechnol. Lett. 2000, 22, 327-330. [CrossRef]

22. González-Rodríguez, J.; Pérez-Juan, P.; Luque De Castro, M.D. Determination of ethanol in beverages by flow injection, pervaporation and density measurements. Talanta 2003, 59, 691-696. [CrossRef]

23. Rostrup, M.; Edwards, J.K.; Abukalish, M.; Ezzabi, M.; Some, D.; Ritter, H.; Menge, T.; Abdelrahman, A.; Rootwelt, R.; Janssens, B.; et al. The methanol poisoning outbreaks in Libya 2013 and Kenya 2014. PLoS ONE 2016, 11, e0152676. [CrossRef] [PubMed] 
24. Neufeld, M.; Lachenmeier, D.W.; Hausler, T.; Rehm, J. Surrogate alcohol containing methanol, social deprivation and public health in Novosibirsk, Russia. Int. J. Drug Policy 2016, 37, 107-110. [CrossRef] [PubMed]

25. International Conference on Harmonization (ICH). ICH Harmonized Tripartite Guideline. Validation of Analytical Procedures: Text and Methodology Q2 (R1), November 2005. Available online: https://www.ich.org/fileadmin/Public_Web_Site/ICH_Products/Guidelines/Quality/Q2_R1/Step4/ Q2_R1_Guideline.pdf (accessed on 16 October 2017).

26. Nikićević, N.; Tešević, V. Possibilities for methanol content reduction in plum brandy. J. Agric. Sci. Belgrade 2005, 50, 49-60. [CrossRef]

27. Pereira, E.V.S.; Oliveira, S.P.A.; Nóbrega, I.C.C.; Lachenmeier, D.W.; Araújo, A.C.P.; Telles, D.L.; Silva, M. Brazilian vodkas have undetectable levels of ethyl carbamate. Quim. Nova 2013, 36, 822-825. [CrossRef]

28. Cole, V.C.; Noble, A.C. Flavour Chemistry. In Fermented Beverage Production; Lea, A.G.H., Piggott, J.R., Eds.; Springer: Boston, MA, USA, 2003; pp. 393-412.

29. Lachenmeier, D.W.; Schoeberl, K.; Kanteres, F.; Kuballa, T.; Sohnius, E.-M.; Rehm, J.; Alcohol Measures for Public Health Research Alliance (AMPHORA). Is contaminated unrecorded alcohol a health problem in the European Union? A review of existing and methodological outline for future studies. Addiction 2011, 106, 20-30. [CrossRef] [PubMed]

30. Boulton, R.B.; Singleton, V.L.; Bisson, L.F.; Kunkee, R.E. Principles and Practices of Winemaking; Springer: Boston, MA, USA, 1999.

31. Falqué, E.; Fernández, E.; Dubourdieu, D. Differentiation of white wines by their aromatic index. Talanta 2001, 54, 271-281. [CrossRef]

32. Lachenmeier, D.W.; Monakhova, Y.B.; Rehm, J. Influence of unrecorded alcohol consumption on liver cirrhosis mortality. World J. Gastroenterol. 2014, 20, 7217-7222. [CrossRef] [PubMed]

33. Lachenmeier, D.W.; Haupt, S.; Schulz, K. Defining maximum levels of higher alcohols in alcoholic beverages and surrogate alcohol products. Regul. Toxicol. Pharmacol. 2008, 50, 313-321. [CrossRef] [PubMed]

34. MacNamara, K.; Hoffmann, A. Gas chromatographic technology in analysis of distilled spirits. Dev. Food Sci. 1998, 39, 303-346.

35. Pérez-Palacios, T.; Petisca, C.; Henriques, R.; Ferreira, I.M. Impact of cooking and handling conditions on furanic compounds in breaded fish products. Food Chem. Toxicol. 2013, 55, 222-228. [CrossRef] [PubMed]

36. Apostolopoulou, A.A.; Flouros, A.I.; Demertzis, P.G.; Akrida-Demertzi, K. Differences in concentration of principal volatile constituents in traditional Greek distillates. Food Control 2005, 16, 157-164. [CrossRef]

37. Papas, R.K.; Sidle, J.E.; Wamalwa, E.S.; Okumu, T.O.; Bryant, K.L.; Goulet, J.L.; Maisto, S.A.; Braithwaite, R.S.; Justice, A.C. Estimating alcohol content of traditional brew in western Kenya using culturally relevant methods: The case for cost over volume. AIDS Behav. 2010, 14, 836-844. [CrossRef] [PubMed]

38. Lachenmeier, D.W.; Leitz, J.; Schoeberl, K.; Kuballa, T.; Straub, I.; Rehm, J. Quality of illegally and informally produced alcohol in Europe: Results from the AMPHORA project. Adicciones 2011, 23, 133-140. [CrossRef] [PubMed]

39. Rehm, J.; Kailasapillai, S.; Larsen, E.; Rehm, M.X.; Samokhvalov, A.V.; Shield, K.D.; Roerecke, M.; Lachenmeier, D.W. A systematic review of the epidemiology of unrecorded alcohol consumption and the chemical composition of unrecorded alcohol. Addiction 2014, 109, 880-893. [CrossRef] [PubMed]

(C) 2017 by the authors. Licensee MDPI, Basel, Switzerland. This article is an open access article distributed under the terms and conditions of the Creative Commons Attribution (CC BY) license (http:/ / creativecommons.org/licenses/by/4.0/). 